\title{
Efeito de coberturas do solo sobre a sobrevivência de Macrophomina phaseolina no feijão-caupi
}

\author{
Cheyla Magdala de Sousa Linhares ${ }^{1,3}$, Francisco Cláudio Lopes de Freitas², Márcia Michelle de Queiroz Ambrósio ${ }^{1}$, \\ Beatriz Letícia Silva da $\mathrm{Cruz}^{1}$, Andréa Mirne de Macêdo Dantas ${ }^{1}$
}

\begin{abstract}
${ }^{1}$ Departamento de Ciências Vegetais, Universidade Federal Rural do Semi-Árido-UFERSA, Campus de Mossoró, RN, CEP: 59.625-900. ${ }^{2}$ Departamento de Fitotecnia, Universidade Federal de Viçosa, Campus de Viçosa, MG, CEP: 36.570-900; ${ }^{3}$ Bolsista Capes.

Autor para correspondência: Cheyla Magdala de Sousa Linhares (cheyla_magdala@hotmail.com).

Data de chegada: 12/11/2014. Aceito para publicação em: 14/04/2015.
\end{abstract}

$10.1590 / 0100-5405 / 2104$

\section{RESUMO}

Linhares C. M. S., Freitas F. C. L., Ambrósio M. M. Q., Cruz, B. L. S., Dantas, A. M. M. Efeito de coberturas do solo sobre a sobrevivência de Macrophomina phaseolina no feijão-caupi. Summa Phytopathologica, v.42, n.2, p.155-159, 2016.

Com o objetivo de avaliar a sobrevivência de Macrophomina phaseolina em solo submetido a diferentes coberturas, conduziu-se dois experimentos em casa de vegetação, no delineamento inteiramente casualizado, em esquema fatorial 5 x 2, com cinco coberturas (Brachiaria brizantha, Pennisetum glaucum, Crotalaria spectabilis, solo coberto com filme de polietileno e solo sem cobertura) e solo esterilizado e não esterilizado. No primeiro experimento, as plantas foram cultivadas em vasos e dessecadas, para posterior plantio do feijão-caupi e no segundo, a semeadura da cultura foi realizada em sucessão ao primeiro cultivo. Nos dois experimentos foram colocadas em cada vaso a $10 \mathrm{~cm}$ de profundidade, no dia do plantio da cultura, quatro bolsas de tecido contendo, cada uma, 10 gramas de inóculo de M. phaseolina, das quais, duas foram retiradas aos 30 dias após o plantio e duas no final do ciclo da cultura, para posterior plaqueamento e determinação da sobrevivência. Realizou-se também o monitoramento das temperaturas máximas e mínimas diárias do solo. Os tratamentos com solo coberto com material vegetal apresentaram menor elevação da temperatura em relação ao solo coberto com filme de polietileno e sem cobertura, que elevaram a temperatura em até 5,9 e $3,9{ }^{\circ} \mathrm{C}$, respectivamente, em relação ao solo coberto com palhada de $P$. glaucum. O solo coberto com filme de polietileno e sem cobertura apresentaram maiores taxas de sobrevivência de M. phaseolina e o solo coberto com palhada de P. glaucum a menor taxa. Maior sobrevivência foi observada no solo não esterilizado.

Palavras-chave: Vigna unguiculata (L.), Cobertura do solo, Patógeno radicular.

\section{ABSTRACT}

Linhares C. M. S., Freitas F. C. L., Ambrósio M. M. Q., Cruz, B. L. S., Dantas, A. M. M.. Effect of soil covers on the survival of Macrophomina phaseolina in cowpea. Summa Phytopathologica, v.42, n.2, p.155-159, 2016.

Aiming to evaluate the survival of Macrophomina phaseolina subjected to different soil covers, two experiments were conducted in a greenhouse, in a completely randomized design, $5 \times 2$ factorial arrangement, with five covers (Brachiaria brizantha, Pennisetum glaucum, Crotalaria spectabilis, polyethylene film and bare soil) and sterilized and unsterilized soil. In the first experiment, the plants were grown in pots and desiccated for subsequent planting of the cowpea, while in the second experiment the culture was sown after the first cultivation. In both experiments, each pot received, at $10 \mathrm{~cm}$ depth, on the day of planting, four fabric bags containing 10 grams of M. phaseolina inoculum each, of which two were removed at
30 days after planting and the other two were removed at the end of the culture cycle for subsequent plating and determination of the survival. Daily maximum and minimum soil temperatures were also monitored. The treatments of soil covered with straw mulch had lower temperature rise in relation to soil covered with polyethylene film and without cover, which raised the temperature up to 5.9 and $3.9^{\circ} \mathrm{C}$, respectively, relative to the soil covered with $P$. glaucum straw. The soil covered with polyethylene film and the soil without cover had higher M. phaseolina survival rates, while the soil covered with P. glaucum straw had the lowest rate. Increased survival was observed in the unsterilized soil.

Keywords: Vigna unguiculata (L.), Soil cover, Root pathogen.

O feijão-caupi [Vigna unguiculata (L.) Walp.] é uma cultura importante para as populações de países subdesenvolvidos, principalmente pela significativa contribuição socioeconômica como suprimento alimentar e fixação de mão de obra no campo (20). No Brasil é amplamente cultivado nas regiões Norte e Nordeste por pequenos produtores, mas nos últimos anos verifica-se o crescimento na produção, sob alta tecnologia (11).

Apesar de ser considerada uma cultura rústica, a mesma é suscetível a diversas doenças, destacando-se a podridão das raízes e podridão cinzenta do caule, causadas pelo fungo Macrophomina phaseolina (Tassi) Goid. (23). Este patógeno foi detectado em mais de 680 espécies vegetais com ampla distribuição geográfica (10). É um habitante natural do solo, de grande variabilidade patogênica e alta capacidade de sobrevivência sob condições adversas, de um ano para o outro em restos de culturas e hospedeiros alternativos, devido a sua capacidade saprofítica e formação de microescleródios que ficam viáveis no solo por muitos anos (14).

Esse patógeno causa sérios problemas em diversas culturas como 
o feijão-comum (Phaseolus vulgaris), melão (Cucumis melo), milho (Zea mays), soja (Glycine Max), feijão-caupi (Vigna unguiculata), entre outras (14), apresentando também diversas espécies de plantas daninhas como hospedeiras alternativas (21).

As condições ambientais que favorecem a ocorrência da doença causada por esse patógeno incluem altas temperaturas e baixo nível de umidade do solo (5). Diante disso, práticas culturais como a cobertura do solo com resíduos vegetais (cobertura morta/palhada) que reduzem o aquecimento $(7,19)$ e a perda de água do solo, mantendo-o em condições de maior umidade em relação ao solo descoberto $(8,22)$ apresentam-se como alternativa para reduzir o potencial de inóculo e a incidência da doença nas culturas.

As gramíneas são mais utilizadas como cobertura morta no sistema de plantio direto, por possuir maior relação $\mathrm{C} / \mathrm{N}$ (carbono/nitrogênio). Trabalhos com feijoeiro e soja têm mostrado redução de alguns fungos habitantes do solo no plantio direto, em comparação com o cultivo convencional (16). De acordo com Toledo-Souza et al. (25) e Görgen et al. (12), a introdução de braquiárias nos sistemas produtivos é bastante útil para o manejo de doenças causadas por patógenos habitantes do solo nessas culturas.

Para Hasna et al. (13), a melhor opção para o manejo de doenças radiculares deve ser o uso de adubos verdes (leguminosas e/ou gramíneas) que reduzam a população dos patógenos no solo. A matéria orgânica no solo pode influenciar na supressividade de doenças, pelo estímulo da atividade da biota, aumentando os agentes de biocontrole e diminuindo o potencial de inóculo dos fitopatógenos, pela ação de compostos liberados durante a decomposição da matéria orgânica (4). Contudo, o filme de polietileno, empregado em cultivo de hortaliças, promovem aquecimento do solo $(7,19)$, podendo potencializar a ocorrência da doença. Cunha (9) relatou que a cobertura do solo com filme de polietileno propiciou aumento de danos provocados pelo fungo M. phaseolina, pois este patógeno é termotolerante, sendo beneficiado por temperaturas elevadas.

Diante disso, esse trabalho teve por objetivo avaliar o efeito de coberturas do solo sobre a sobrevivência de Macrophomina phaseolina no feijão-caupi.

\section{MATERIAL E MÉTODOS}

Foram conduzidos dois experimentos em casa de vegetação em Mossoró-RN (5'11' 17' Sul, $37^{\circ} 20^{\prime} 39^{\prime}$ " Oeste), sendo o primeiro de março a maio, e o segundo de junho a agosto, ambos em 2013.

O delineamento experimental foi o inteiramente casualizado, em um esquema fatorial $5 \times 2$, com quatro repetições. Os tratamentos foram constituídos por cinco tipos de cobertura do solo [Braquiária (Brachiaria brizantha); Milheto (Pennisetum glaucum); Crotalária (Crotalaria spectabilis); solo coberto com filme de polietileno e solo sem cobertura] e solo esterilizado e não esterilizado.

Cada unidade experimental foi constituída por vasos com $18 \mathrm{~L}$ de solo coletado em área nativa da Caatinga, no município de Mossoró$\mathrm{RN}$, composta, principalmente por plantas de catanduva (Piptadenia moniliformis Benth), mulungú (Erythrina mulungu Marth) e sabiá (Mimosa caesalpiniaefolia Benth). Após a coleta, o solo foi passado em peneira de 4,0 $\mathrm{mm}$. Posteriormente, o solo que iria passar pelo processo de esterilização, foi previamente umedecido até atingir cerca de $70 \%$ da capacidade de campo. Esse foi autoclavado duas vezes, em intervalos de $24 \mathrm{~h}$, durante uma hora à temperatura de $121^{\circ} \mathrm{C}$.

Antes de ser colocado nos vasos, incorporou-se aos solos, com e sem esterilização, 2,0 $\mathrm{kg} \mathrm{m}^{-3}$ da formulação N-P-K - 04-14-08 e 3,0 kg $\mathrm{m}^{-3}$ de superfosfato simples. A semeadura das coberturas vegetais foi realizada em épocas diferentes, tendo em vista a diferença de ciclo entre as espécies. Primeiro semeou-se a braquiária e vinte dias após, o milheto e a crotalária. Por ocasião da floração da crotalária e do milheto, 50 dias após o semeio destas e 70 dias após o semeio da braquiária, as plantas foram dessecadas com o glyphosato $\left(1.020 \mathrm{~g} \mathrm{ha}^{-1}\right)$, com pulverizador costal manual, calibrado para aplicar volume de calda de $100 \mathrm{~L} \mathrm{ha}^{-1}$.

Os tratamentos solo sem cobertura e solo coberto com filme de polietileno foram mantidos sem vegetação durante o período de crescimento das plantas de cobertura, sendo que o filme de polietileno (lona de plástico preto) foi colocado sobre a superfície dos vasos, antes da semeadura do feijão-caupi. Para permitir a semeadura, emergência das plântulas e a irrigação, foram efetuados três orifícios, com diâmetro de 3,0 cm, no filme plástico contido nos vasos pré-determinados.

Aos 15 dias após a dessecação, quando as plantas de cobertura encontravam-se secas, estas foram cortadas rente ao solo, levadas à estufa com circulação forçada de ar à temperatura de $65^{\circ} \mathrm{C}$ até obtenção de massa constante, para determinação da massa seca da palhada e, recolocadas sobre os respectivos vasos. Posteriormente realizou-se a semeadura do feijão-caupi, cultivar BRS Guariba, colocando-se seis sementes por vaso a $3,0 \mathrm{~cm}$ de profundidade, após a emergência desbastou-se mantendo três plantas por vaso.

$\mathrm{O}$ inóculo foi produzido a partir do isolado de M. phaseolina proveniente do departamento de Ciências Vegetais da UFERSA, obtido de planta doente de feijão-caupi, com sintomas de podridão seca. Foi realizado o teste de patogenicidade em plantas de feijão caupi, antes da produção de inóculo. Após o aparecimento dos sintomas nas plantas, foi realizado o isolamento do patógeno e, cultivado em meio BDA (batata-dextrose-ágar) + tetraciclina $(0,05 \mathrm{~g} / \mathrm{L})$. Posteriormente, o fungo foi repicado para substrato areno-orgânico, esterilizado, composto de três partes de esterco bovino curtido, uma parte de areia lavada e $2 \%$ de aveia (v/p), onde foram adicionados $20 \mathrm{~mL}$ de água destilada para cada $100 \mathrm{~mL}$ de substrato (15).

Os frascos, de material plástico e capacidade de $1 \mathrm{~L}$, contendo o substrato com o patógeno foram mantidos no escuro, por quinze dias, em estufa tipo BOD a $32{ }^{\circ} \mathrm{C}$, sendo periodicamente agitados com o objetivo de homogeneizar a infestação. Antes da infestação do solo foi realizado o plaqueamento do inóculo (substrato infestado com as estruturas do fungo) para testar a sua viabilidade.

Concomitantemente à semeadura do feijão-caupi, foram enterradas a $10 \mathrm{~cm}$ de profundidade, em cada vaso, quatro bolsas de tecido sintético (náilon) contendo cada uma $10 \mathrm{~g}$ de inóculo de $M$. phaseolina. As bolsas foram amarradas com linha de náilon e identificadas em sua extremidade livre com fita crepe para facilitar a retirada das mesmas.

Em cada tratamento foram instalados sensores tipo termopares de cobre-constantan, a $5 \mathrm{~cm}$ de profundidade, para monitorar a temperatura do solo. Os dados foram coletados a cada 10 min e armazenados em dataloggers Campbell CR 1000. A partir dos registros obtidos, avaliouse, para cada intervalo de uma semana, durante o período de 3 a 10 semanas, a média das temperaturas máxima e mínima diárias.

A avaliação da sobrevivência de $M$. phaseolina foi realizada aos 30 dias após a emergência e no final do ciclo da cultura (65 dias após o plantio). Em cada época, foram retiradas do solo infestado com o patógeno, duas bolsas de cada vaso e, posteriormente, realizadas desinfestações superficiais das mesmas, com solução de álcool a $70 \%$ por $5 \mathrm{~s}$, solução de hipoclorito de sódio a $1,5 \%$, por $20 \mathrm{~s}$ e água destilada esterilizada. Em seguida, foi realizado o plaqueamento em meio de cultura intitulado, RB modificado (17), semi-seletivo para $M$. phaseolina e elaborado na proporção de $39 \mathrm{~g}$ de BDA (Batata dextrose agar), previcur $(0,5 \mathrm{~mL})$, rifampicina $(100 \mathrm{mg})$ e $1000 \mathrm{~mL}$ de água 
destilada e esterilizada.

Foram transferidos, com auxílio de uma pinça devidamente esterilizada, dez porções do inóculo desinfestado para placas contendo o referido meio. Para cada bolsa foram elaboradas cinco placas. Estas foram mantidas por seis dias em estufa a $32{ }^{\circ} \mathrm{C}$, no escuro, para em seguida, serem contados os sobreviventes que se manifestaram através do crescimento do micélio em torno da porção plaqueada. No final do ciclo foi repetido esse mesmo procedimento para as demais bolsas. Os dados da sobrevivência foram submetidos à análise pelo teste $\mathrm{F}$ e em caso de significância, as médias foram comparadas pelo teste de Tukey a $5 \%$ de probabilidade.

Aos 20 dias após a colheita do primeiro ciclo do feijão-caupi, procedeu-se a nova pesagem das coberturas para determinar a decomposição e realizou-se nova semeadura da cultura, nos mesmos vasos, com as respectivas coberturas da fase anterior. O inóculo do patógeno e as bolsas foram confeccionadas e, instaladas nos vasos, conforme o experimento I. A condução da cultura e as avaliações de sobrevivência do patógeno também seguiram os mesmos procedimentos do primeiro cultivo.

\section{RESULTADOS E DISCUSSÃO}

O milheto foi a cobertura que apresentou maior produção de palhada, seguido pela braquiária, enquanto que a crotalária apresentou menores índices de cobertura (Tabela1). Além da maior produção de palhada, as gramíneas (milheto e braquiária) possuem maior relação carbono/nitrogênio e maior teor de lignina em relação à crotalária, levando mais tempo para decompor e, consequentemente, cobrindo o solo por mais tempo, conforme pode ser constatado pela baixa quantidade de massa seca da leguminosa por ocasião da colheita do primeiro cultivo e plantio do segundo cultivo. Estes resultados corroboram com Braz (6) que avaliando o tempo de decomposição da palhada de diferentes espécies de cobertura do solo, verificaram que a meia vida, ou seja, o tempo necessário para decomposição de $50 \%$ da massa seca da palhada de $B$. brizantha e Crotalaria sp. foi de 140 e 45 dias após a dessecação, respectivamente.

A maior quantidade de palhada cobrindo o solo durante o primeiro cultivo do feijão-caupi nos tratamentos com milheto e braquiária, foi consequência do maior acúmulo de massa seca e da menor taxa de decomposição (Tabela 1), resultando em maior proteção do solo da incidência da radiação solar e menor aquecimento, conforme pode ser constatado na Figura 1A, enquanto que, os tratamentos com cobertura de filme de polietileno e sem cobertura apresentaram maior elevação da temperatura, com diferença de até 5,9 e $3,9^{\circ} \mathrm{C}$ em relação ao solo coberto com palhada de milheto, respectivamente, na $7^{\mathrm{a}}$ semana após o plantio do feijão-caupi.

Coelho et al. (7) avaliando o efeito de coberturas orgânicas e inorgânicas sobre a temperatura do solo, em condições de campo, verificaram que os solos cobertos com filme de polietileno e sem cobertura apresentaram elevação na temperatura máxima diária, a 5 $\mathrm{cm}$ de profundidade, na ordem de 8 e $5,5^{\circ} \mathrm{C}$, respectivamente, em comparação com o solo mantido com cobertura morta de Brachiaria brizantha.

A temperatura mínima diária apresentou pouca variação entre as coberturas avaliadas durante o período experimental (Figura $1 \mathrm{~B}$ ), embora seja possível perceber que o solo sem cobertura foi o que apresentou menores valores, enquanto que os tratamentos com maior quantidade de palhada, milheto e braquiária, que apresentaram menor aquecimento, resultaram também em menor perda de temperatura durante a noite, indicando que a cobertura morta, reduz tanto o aquecimento quanto a perda de calor, reduzindo a amplitude térmica do solo no decorrer do dia. Estes resultados corroboram com Coelho et al. (8) onde verificaram que a cobertura morta do solo no cultivo de pimentão em plantio direto reduziu a amplitude térmica do solo em relação ao solo sem cobertura e com filme de polietileno, no plantio convencional.

No primeiro cultivo do feijão-caupi, os tratamentos com o filme de polietileno e o solo sem cobertura apresentaram maior sobrevivência de M. phaseolina aos 30 dias após o plantio (DAP) (Tabela 2), devido à maior temperatura do solo (Figura 1A), enquanto que o solo coberto com palhada de milheto apresentou menores índices de sobrevivência, indicando o efeito positivo dessa cobertura no manejo do patógeno, que proporcionou o menor aquecimento (Figura 1A), devido a maior quantidade de massa de palhada produzida (Tabela 1), atuando na manutenção da umidade do solo, criando assim condições desfavoráveis ao patógeno que se adapta melhor em solos com altas temperaturas e pouca umidade (3).

Outra possível explicação para redução da sobrevivência do patógeno no tratamento com cultivo de milheto para formação de palhada é a inativação do fungo, devido provavelmente à liberação de compostos tóxicos. Resultado semelhante também foi observado por Pereira Neto \& Blum (18) quando utilizaram palha de milheto ao solo, para a redução da podridão do colo do feijoeiro, causado pelo patógeno Sclerotium rolfsii, também considerado um patógeno habitante do solo e de difícil controle. Esses pesquisadores observaram tendência significativa de redução da doença e justificaram que pode ter sido devido ao aumento da população estimada de Pseudomonas do grupo fluorescente. Para os tratamentos com braquiária e crotalária, o índice de sobrevivência foi intermediário.

Ainda para o primeiro cultivo, não se verificou diferença na sobrevivência do fitopatógeno M. phaseolina, na avaliação realizada

Tabela 1. Massa seca de palhada (gramas vaso ${ }^{-1}$ ) por ocasião do plantio do feijão-caupi no primeiro e no segundo cultivo.

\begin{tabular}{|c|c|c|c|c|}
\hline \multirow{2}{*}{ Cobertura } & \multicolumn{2}{|c|}{$1^{\circ}$ cultivo } & \multicolumn{2}{|c|}{$2^{\circ}$ cultivo } \\
\hline & Esterilizado & Não esterilizado & Esterilizado & Não esterilizado \\
\hline Braquiária & $154,0 \mathrm{~b}$ & $125,5 \mathrm{~b}$ & $26,97 \mathrm{~b}$ & $27,82 \mathrm{~b}$ \\
\hline Milheto & $357,7 \mathrm{a}$ & $280,2 \mathrm{a}$ & 53,5 a & $43,61 \mathrm{a}$ \\
\hline Filme de polileno & - & - & - & - \\
\hline
\end{tabular}

Médias seguidas pelas mesmas letras nas colunas não diferem entre si pelo teste Tukey a $5 \%$ de probabilidade. 

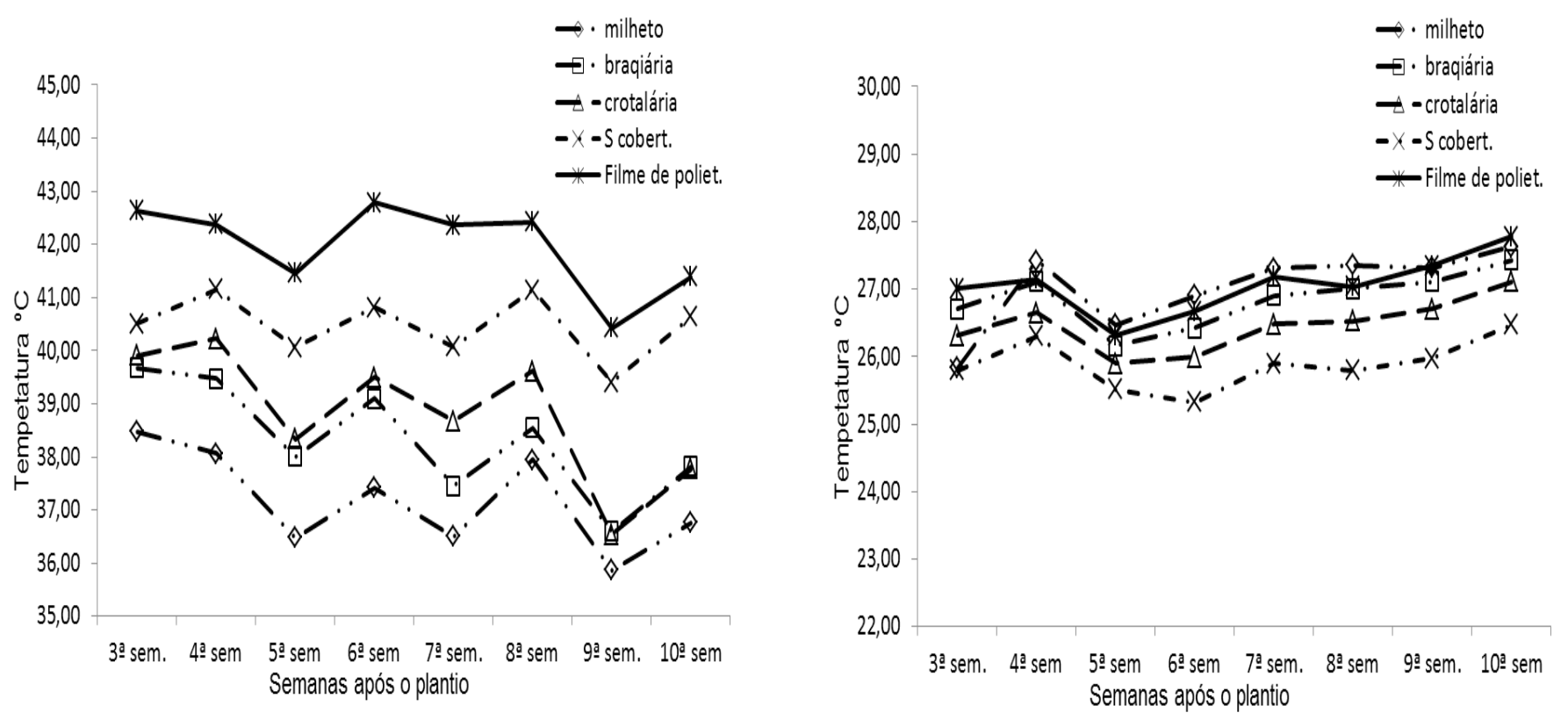

Figura 1. Média semanal das temperaturas máximas (A) e mínimas (B) diárias do solo, sob diferentes coberturas no período de três a 10 semanas após o plantio do feijão-caupi, no primeiro cultivo.

Tabela 2. Efeito de diferentes coberturas na sobrevivência de Macrophomina phaseolina em dois cultivos sucessivos com feijão-caupi e dois tipos de utilização do solo.

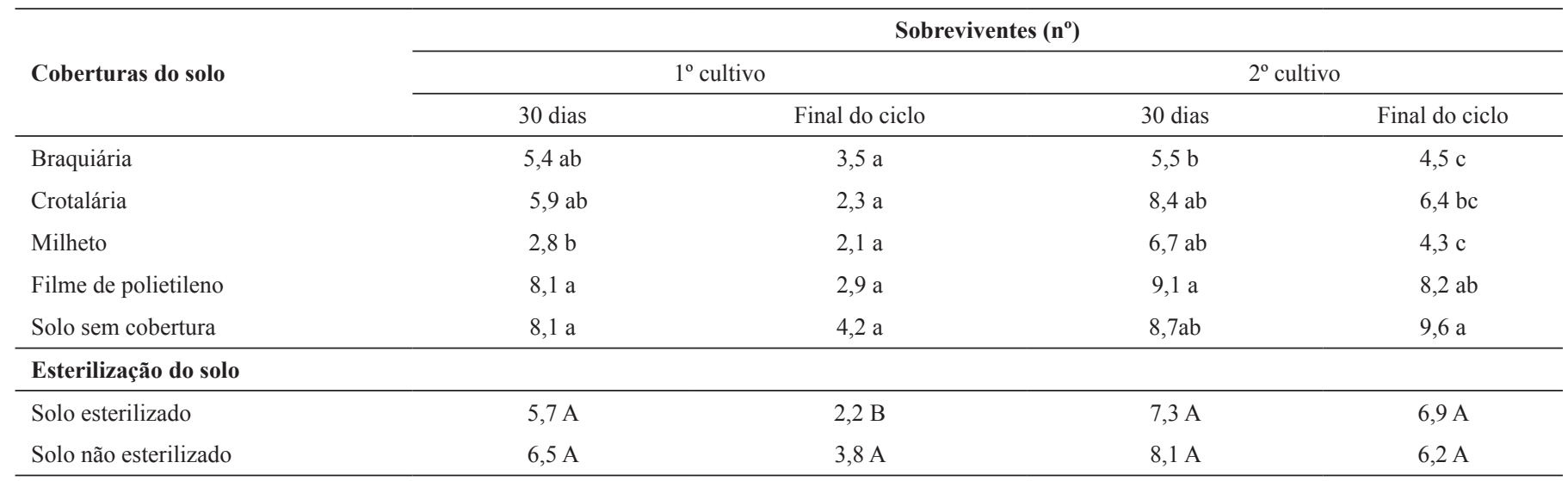

Nas colunas, letras minúsculas comparam as médias entre as diferentes coberturas de solo pelo teste de Tukey a $5 \%$ de probabilidade e, letras maiúsculas, comparam as médias entre os solos esterilizado e não esterilizado pelo teste $\mathrm{F}$.

por ocasião da colheita ( 65 dias) entre os diferentes tipos de cobertura, entretanto, os níveis de sobrevivência foram inferiores aos 30 dias ( $1^{a}$ coleta). Uma das possíveis causas dessa redução é que, com o crescimento da cultura ocorre o sombreamento do solo, reduzindo a incidência direta da radiação solar e consequente redução do aquecimento do solo, além da redução da taxa evaporativa do solo, mantendo-o com melhores níveis de umidade, condição prejudicial ao desenvolvimento do patógeno (5).

No segundo cultivo do feijão-caupi, menores índices de sobrevivência do patógeno $M$. phaseolina foram verificados nos tratamentos com as gramíneas, milheto e braquiária, em relação ao solo coberto com filme de polietileno, sem cobertura e cultivado com crotalária (Tabela 2), sendo que esta última é uma leguminosa com baixa relação $\mathrm{C} / \mathrm{N}$, o que propicia rápida decomposição, resultando em baixa cobertura do solo no segundo cultivo, conforme pode ser constatado na Tabela 1.

Vantagens têm sido constatadas com plantas de cobertura no plantio direto. Além da produção de fitomassa, as plantas utilizadas nesse sistema podem também liberar grandes quantidades de nutrientes na superfície, após sua decomposição (24), e a secreção de compostos específicos podem incentivar relações simbióticas ou podem inibir associações patogênicas (2). Assim, com o aumento da população microbiana antagônica, há maior produção de metabólitos que podem possuir efeito fungistático.

Com relação à esterilização do solo, observou-se que os tratamentos em que o solo passou pelo processo de esterilização, no geral, apresentaram menor número de sobreviventes, para os dois cultivos analisados, apresentando, no primeiro ensaio, diferença estatística significativa, no final do ciclo da cultura. Embora o esperado fosse que no solo obtido de área nativa e, não esterilizado, houvesse menor 
número de sobreviventes, uma vez que, normalmente nesse solo ocorre maior número de microrganismos antagonistas, o que não ocorreu provavelmente devido à presença do fitopatógeno $M$. phaseolina no solo, inclusive adaptado ao ambiente.

Para Almeida et al. (1), não se pode ignorar a diversidade genética de populações nativas de M. phaseolina naturalmente encontrados em solos "virgens" que ao longo dos anos infectaram culturas comerciais, logo que esses solos foram utilizados para finalidade comercial. Portanto, é possível supor que o solo não esterilizado, utilizado no presente trabalho, apresentava $M$. phaseolina apto a infectar o hospedeiro, dessa forma, com a infestação artificial ocorreu o aumento do potencial de inóculo no referido solo.

O presente estudo demonstrou que, o solo coberto com milheto foi o que apresentou maior redução na sobrevivência do fungo Macrophomina phaseolina e o solo coberto com filme de polietileno e solo sem cobertura apresentaram as maiores médias de sobrevivência. E que, a maior sobrevivência de M. phaseolina foi observada no solo não esterilizado em relação ao esterilizado.

\section{REFERENCIAS}

1. Almeida, A. M. R.; Abdelnoor, R. V.; Arrabal Arias, C. A.; Carvalho, V. P.; Jacoud Filho D. S.; Marin, R. R.; Benato, L. C.; Pinto, M. C.; Carvalho, C. G. P. Genotypic diversity among Brazilian isolates of Macrophomina phaseolina revealed by RAPD. Fitopatologia Brasileira, Brasília, v. 28, n. 3, p. 279-85, 2003.

2. Bais, H. P.; Prithiviraj, B.; Jha, A. K.; Ausubel, F. M.; Vivanco, J. M. Mediation of pathogen resistance by exudation of antimicrobials from roots. Nature, Londres, v. 434, n. 434, p. 217-221, 2005.

3. Basseto, M. A.; Bueno, C. J.; Chagas, H. A.; Rosa, D. D.; Padovani, C. R.; Furtado, E. L. Efeitos da simulação da solarização do solo com materiais vegetais sobre o crescimento micelial de fungos fitopatogênicos habitantes do solo. Summa Phytopathologica, Botucatu, v. 37, n.3, p. 116-120, 2011.

4. Bettiol, W.; Morandi, M. A. B. Biocontrole de doenças de plantas: uso e perspectivas. In: Bettiol, W.; Ghini, R.; Mariano, R. R. L.; Michereff, S. J.; Mattos, L. P. V.; Alvarado, I. C. M.; Pinto, Z. V. Supressividade a fitopatógenos habitantes do solo. Jaguariúna: Embrapa Meio-Ambiente, 2009. v.1, cap.12, p. 187-208.

5. Bianchini, A.; Maringoni, A. C.; Carneiro, S. M. P. G. Doenças do feijoeiro (Phaseoluls vulgaris L.). In: Kimati, H., Amorim, L., Rezende, J. A. M., Bergamin Filho, A.; Camargo, L. E. A. Manual de Fitopatologia. São Paulo: Editora Ceres, 2005. v.2, cap. 34, p. 333-349.

6. Braz, A. J. B. P. Fitomassa e decomposição de espécies de cobertura do solo e seus efeitos na resposata do feijoeiro e do trigo ao nitrogênio. 2003. 72 f. Tese (Doutorado em Agronomia) - Escola de Agronomia e Engenharia de Alimentos, Universidade Federal de Goiás, Goiânia.

7. Coelho, M. E. H.; Freitas, F. C. L.; Cunha, J. L. X. L.; Silva, K. S.; Grangeiro, L. C.; Oliveira, J. B. Coberturas do solo sobre a amplitude térmica e a produtividade de pimentão. Planta Daninha, Viçosa, v. 31, n. 2, p. 369-378, 2013a.

8. Coelho, M. E. H. Freitas, F. C. L.; Cunha, J. L. X. L.; Medeiros, J. F.; Silva, M. G. O. Production and efficiency of water usage in capsicum crops under no-tillage and conventional planting systems. Revista Ciência Agronômica, Fortaleza, v. 44, n. 4, p. 741-749, 2013 b.
9. Cunha, J. L. X. L.. Sistemas de plantio no manejo de plantas daninhas e na comunidade microbiana do solo na cultura do pimentão. 2012. 106 f. Tese (Doutorado em Fitotecnia) - Universidade Federal Rural do Semi-Árido (UFERSA), Mossoró.

10. Farr, D. F.; Rossman, A. Y.; Palm, M. E.; McCray, E. B. Fungus-host distribution database. 2010. Disponível em: <http://nt.ars-grin.gov/ fungaldatabases/ >. Acesso em: 2 jun. 2013.

11. Freire Filho, F. R. Feijão-caupi no Brasil: produção, melhoramento genético, avanços e desafios. 1. ed. Teresina: Embrapa Meio-Norte, 2011. v.1, 84 p.

12. Görgen, C.A.; Silveira Neto, A.N. da; Carneiro, L.C.; Ragagnin, V.A.; Lobo Junior, M. Controle do mofo-branco com palhada e Trichoderma harzianum 1306 em soja. Pesquisa Agropecuária Brasileira, Brasília, v. 44, n. 12, p.1583-1590, 2009.

13. Hasna, M. K.; Martensson, A.; Persson, P.; Rämert, B. Use of compost to manage corky root disease in organic tomato production. Annals of Applied Biology, Hoboken, v. 151, n. 3, p. 381-390, 2007.

14. Kimati, H.; Amorim, L.; Rezende, J. A. M.; Bergamin Filho, A.; Camargo, L. E. A. Manual de Fitopatologia: Doenças das Plantas Cultivadas. 4. ed. São Paulo: Agronômica Ceres, 2005. v. 2, 663 p.

15. Lefèvre, A. F.; Souza, N. L. Determinação da temperatura letal para Rhizoctonia solani e Sclerotium rolfsii e efeito da solarização sobre a temperatura do solo. Summa Phytopathologica, Botucatu, v. 19, n. 2, p. 107-112, 1993.

16. Napoleão, R.; Café Filho, A. C.; Nasser, L. C. B.; Lopes, C. A. ${ }^{\text {IV; }}$ Silva H. R. Intensidade do mofo-branco do feijoeiro em plantio convencional e direto sob diferentes lâminas d'água. Fitopatologia Brasileira, Brasília, v.30, n. 4, p.374-379, 2005.

17. Nascimento, S. R. C.; Ambrósio, M. M. Q.; Silva, F. H. A. S.; Guimarães, L. M. S. Meios de cultura semi-seletivos para Macrophomina phaseolina. Summa Phytopathologica, Botucatu, v. 40, n. 4, p. 334-337, 2014.

18. Pereira Neto, J. V.; Blum, L. E. B. Adição de palha de milheto ao solo para redução da podridão do colo em feijoeiro. Pesquisa Agropecuária Tropical, Goiânia, v. 40, n. 3, p. 354-361, 2010.

19. Resende, F. V.; Souza, L. S.; Oliveira, P. S. R.; Gualberto, R. Uso de cobertura morta vegetal no controle da umidade e temperatura do solo, na incidência de plantas invasoras e na produção da cenoura em cultivo de verão. Ciência Agrotécnica, Lavras, v.29, n.1, p.100-105, 2005.

20. Rocha, M. de M.; Carvalho, K. J. M.; Freire Filho, F. R.; Lopes, A. C. A.; Gomes, R. L. F.; SOUSA, I, S. Controle genético do comprimento do pedúnculo em feijão-caupi. Pesquisa Agropecuária Brasileira, Brasília, v. 44 , n. 3 , p. $270-275,2009$.

21. Rodrigues, A. P. M. S. Ocorrência de plantas daninhas como hospedeiras alternativas de fitopatógenos radiculares e avaliação da patogenicidade sobre as culturas do melão e da melancia. 2013. 76 f. Dissertação (Mestrado em Fitotecnia) - Universidade Federal Rural do Semi-Árido, Mossoró.

22. Teófilo, T. M. S.; Freitas, F. C. L.; Medeiros, J. F.; Fernandes, D.; Grangeie ro, L. C.; Tomaz, H. V. Q.; Rodrigues, A. P. M. S. Eficiência da Água e Interferência de Plantas daninhas no meloeiro cultivado nos Sistemas de Plantio Direto e convencional. Planta daninha, Viçosa, v 30, n.3, p.547-556, 2012.

23. Torres, S. B.; Bringel, J. M. M. Avaliação da qualidade sanitária e fisiológica de sementes de feijão macassar. Caatinga, Mossoró, v.18, n.2, p.88-92, 2005.

24. Torres, J. L. R.; Pereira, M. G. Dinâmica do potássio nos resíduos vegetais de plantas de cobertura no cerrado. Revista Brasileira de Ciência do Solo, Viçosa, v.32, n.4, p. 1609-1618, 2008.

25. Toledo-Souza, E. D. ; Silveira, P. M.; Lobo Junior, M.; Café Filho, A.C. Sistemas de cultivo, sucessões de culturas, densidade do solo e sobrevivência de patógenos de solo. Pesquisa Agropecuária Brasileira, Brasília, v.43, n. 8, p.971-978, 2008. 